\title{
STUDY OF ACCESSORY RENAL VESSELS AND THEIR CLINICAL SIGNIFICANCE IN CADAVERS
}

\author{
Udayasree $L^{1}$, Maheswari K. $B^{2}$, Ravindranath $G^{3}$, Siva Prasad G. $V^{4}$
}

${ }^{1}$ Associate Professor, Department of Anatomy, NRIIMS, Visakhapatnam.

${ }^{2}$ Tutor, Department of Anatomy, NRIIMS, Visakhapatnam.

${ }_{3}^{3}$ Professor and HOD, Department of Anatomy, NRIIMS, Visakhapatnam.

${ }^{4}$ Associate Professor, Department of Anatomy, NRIIMS, Visakhapatnam.

\section{ABSTRACT}

\section{BACKGROUND}

A single renal artery supplies each kidney on either side after arising from the abdominal aorta. Presence of accessory renal vessels is the most common variation in the blood supply of kidney.

Aim- The present study was done to study the variations in the pattern of arrangement of hilar structures, blood supply of kidneys and their embryological \& clinical significance.

\section{MATERIALS AND METHODS}

The present study was done on 60 kidneys of 30 embalmed human cadavers in the Department of Anatomy, NRIIMS, Visakhapatnam. The anomalous origin of renal vessels and change in the pattern of arrangement of hilar structures were observed during routine dissection for undergraduate students.

\section{RESULTS}

In the present study, we observed accessory renal vessels in four kidneys which were unilateral in two, bilateral in one cadaver and one was associated with horseshoe kidney.

\section{CONCLUSION}

The knowledge of accessory renal vessels is important to the urologists and surgeons to do various procedures in the vicinity of kidneys and on the kidneys.

\section{KEYWORDS}

Kidney, Accessory Renal Vessels, Horseshoe Kidney, Hilar Structures.

HOW TO CITE THIS ARTICLE: Udayasree L, Maheswari KB, Ravindranath G, et al. Study of accessory renal vessels and their clinical significance in cadavers. J. Evolution Med. Dent. Sci. 2017;6(9):687-689, DOI: 10.14260/Jemds/2017/148

\begin{abstract}
BACKGROUND
Kidneys are vital organs. Each kidney is supplied by a renal artery, which is a branch of abdominal aorta. Right renal artery is longer than the left one. ${ }^{1}$ They carry about $20 \%$ of cardiac output to supply the kidneys. ${ }^{2}$ They branch laterally from the aorta just below the origin of the superior mesenteric artery. Anatomical variations in the renal vasculature are common and occur in $25 \%$ to $40 \%$ of kidneys. The most common variation in the accessory renal arteries occur in 20 to $25 \%$ of people. A lower pole artery is the commonest and bilateral in $15 \% .^{3}$ This occurs more often on the left. These additional arteries can enter through the hilum or directly into the parenchyma. Lower pole arteries can cross anterior to the pelvis of ureter causing ureteropelvic junction obstruction. ${ }^{4}$ The presence of accessory renal arteries have clinical significance. These are considered during some surgical procedures like partial nephrectomy, endoscopic pyeloplasty and live renal transplantation. They
\end{abstract}

Financial or Other, Competing Interest: None.

Submission 22-12-2016, Peer Review 13-01-2017,

Acceptance 21-01-2017, Published 30-01-2017.

Corresponding Author:

Dr. L. Udayasree,

D. No.53-38-7/3/11,

SF1 - Siva Karthik Residency,

Behind Maddilapalem Sivalayam,

KRM Colony, Maddilapalem,

Visakhapatnam-530013.

E-mail: thesensitiveramesh@gmail.com

DOI: $10.14260 /$ jemds $/ 2017 / 148$

(c) $($ ()) $\odot$ are common in horseshoe and crossed fused kidneys. ${ }^{5}$ The accessory renal arteries are end arteries. If they are damaged or ligated during surgical procedures in the abdomen, the part of kidney supplied by it is likely to become ischaemic. ${ }^{6}$

The large renal veins lie anterior to renal arteries and open into the inferior vena cava at right angles. The left one is longer than the right one. The accessory renal veins occur in up to 1 in 8 live births and are often retroaortic on left side.

\section{MATERIALS AND METHODS}

The present study was done on 60 kidneys of 30 embalmed adult human cadavers during routine dissection for MBBS undergraduate students in the Department of Anatomy, NRIIMS, Sangivalasa, Visakhapatnam. Abdomen was dissected according to the methods described by Romanees GJ,7 and kidneys along with renal vessels were exposed, cleaned and observed for the main renal vessels, accessory renal vessels and the pattern of arrangement of renal pedicles at the hilum.

\section{RESULTS}

The present study was conducted on 60 kidneys of 30 embalmed human cadavers and the following observations were made. A single renal artery supplying each kidney was observed in 27 cadavers and accessory renal arteries were observed in 3 cadavers. One cadaver had bilateral multiple accessory renal arteries and accessory renal vein on right side (Figure 3), one had accessory renal artery on left side (figure 1), one had horseshoe kidney with accessory renal vessels on left side only (Figure 2) and altered arrangement 
of hilar structures in one cadaver (Figure 4). These are arranged from anterior to posterior - renal artery, renal vein and pelvis of ureter.

\begin{tabular}{|c|c|c|c|c|}
\hline $\begin{array}{c}\text { Name of } \\
\text { the } \\
\text { Structure }\end{array}$ & Cadavers & $\begin{array}{c}\text { Bi- } \\
\text { lateral }\end{array}$ & $\begin{array}{c}\text { Uni- } \\
\text { lateral }\end{array}$ & $\begin{array}{c}\text { Unilateral } \\
\text { with } \\
\text { Horseshoe } \\
\text { Kidney }\end{array}$ \\
\hline $\begin{array}{c}\text { Accessory } \\
\text { renal artery }\end{array}$ & 3 & 1 & 1 (left) & 1 (left) \\
\hline $\begin{array}{c}\text { Accessory } \\
\text { renal vein }\end{array}$ & 2 & & 1 (right) & 1 (left) \\
\hline $\begin{array}{c}\text { Altered hilar } \\
\text { structures }\end{array}$ & 1 & & 1 (right) & \\
\hline \multicolumn{2}{|c|}{ Table 1. Showing Number of Accessory Renal Vessels } \\
\hline
\end{tabular}

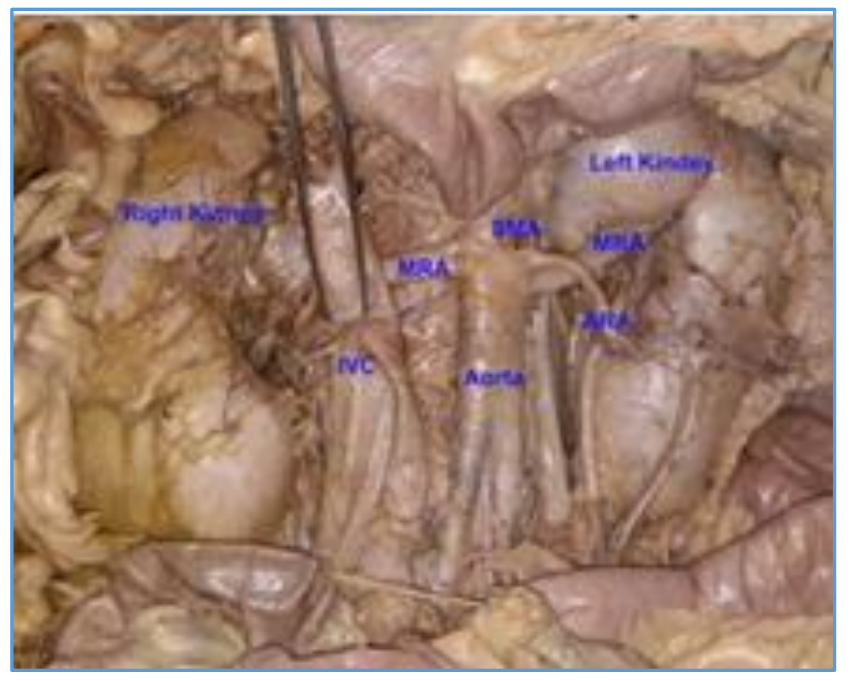

Figure 1. Showing Accessory Renal Artery on Left Side

(SMA - superior mesenteric artery, MRA - main renal artery, IVC - inferior vena cava, ARA - accessory renal artery)

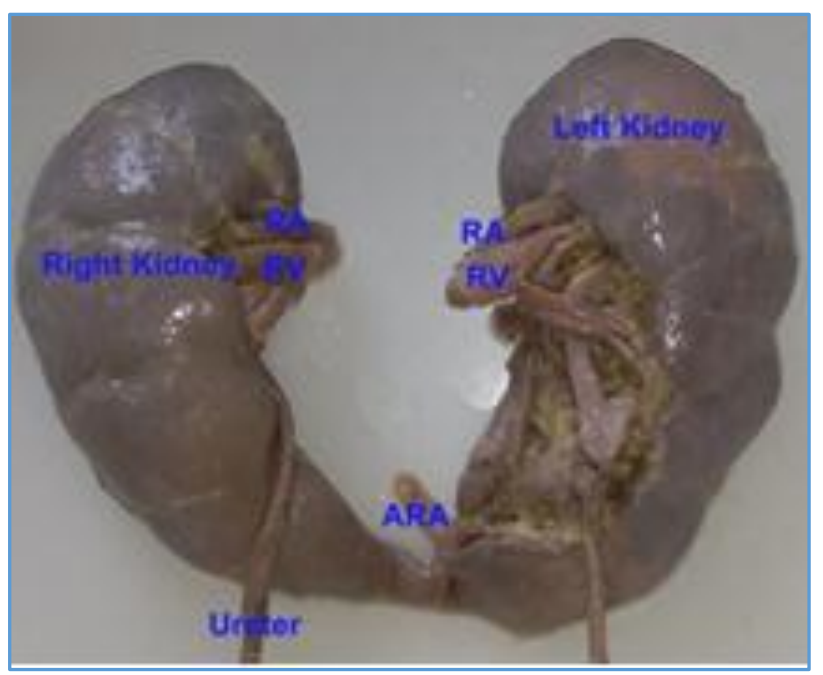

Figure 2. Showing Accessory Renal Vessels Associated with Horseshoe Kidney

(RA - renal artery, RV - renal vein, ARA - accessory renal artery)

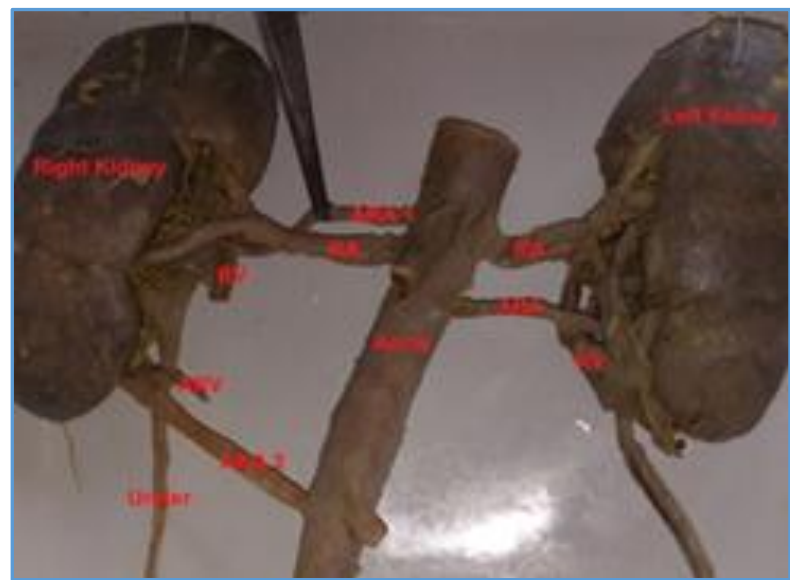

Figure 3. Showing Multiple Accessory Renal Vessels Bilaterally

(RA - renal artery, RV - renal vein, ARA - accessory renal artery, ARV - accessory renal vein)

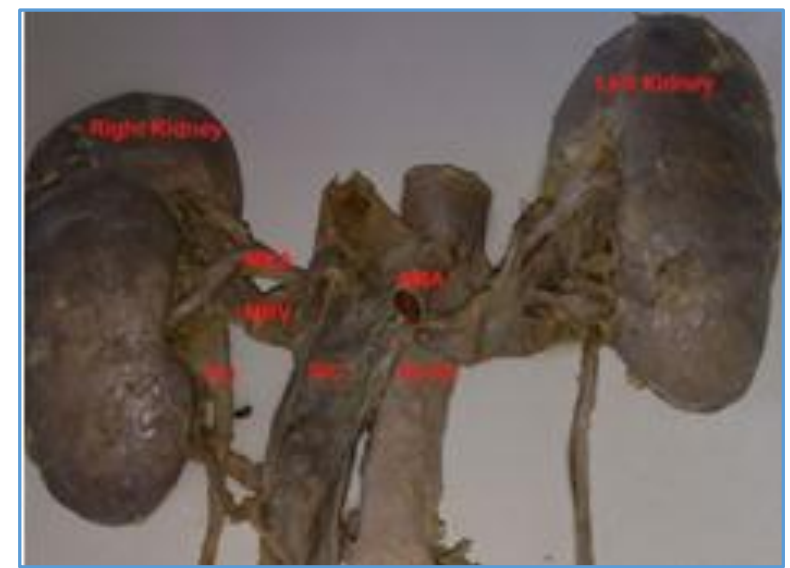

Figure 4. Showing Altered Hilar Structures on Right Side

(MRA - main renal artery, MRV - main renal vein, SMA superior mesenteric artery, IVC - inferior vena cava, PU pelvis of ureter)

\section{DISCUSSION}

The accessory renal artery is the precocious origin of a segmental artery which sometimes arises from the aorta and supplies upper or lower pole of the kidney. It represents the persistent mesonephric artery. ${ }^{8}$ The artery to the lower pole usually passes anterior to the pelvis of ureter and may cause obstruction to the flow of urine producing hydronephrosis. Benzamin J. Lee et $\mathrm{al}^{9}$ reported a case of renovascular hypertension with unilateral hydronephrosis and ureteropelvic junction obstruction due to an accessory renal artery crossing the ureter.

In the present study, unilateral accessory renal artery was present in one cadaver. It was directly arising from aorta just below the origin of superior mesenteric artery and above the left main renal artery on left side and enters the kidney through the hilum. In one case accessory renal artery on the left side was associated with horseshoe kidney. According to Julian Kabala and Carl Roobottom, ${ }^{5}$ accessory renal arteries were usually associated with horseshoe kidney and crossed fused kidney. Gyata Mehta and Vasanti Arole ${ }^{10}$ stated that 
accessory renal arteries were most commonly found $(63.63 \%)$ on left side than on the right.

In the present study, one cadaver had bilateral multiple accessory renal arteries. Two accessory renal arteries were present on each side. Both were arising from the abdominal aorta, one was above and one was arising below the main renal arteries. Upper arteries followed the main arteries to the hilum and lower arteries directly reached the lower pole. According to Kadir S, 11 multiple renal arteries were unilateral in approximately $30 \%$ of patients and bilateral in approximately $10 \%$. Accessory renal vessels to the polar regions are usually smaller than the accessory hilar renal arteries which were equal in size to a main renal artery.

In the present study, we observed unilateral alteration of hilar structures in one cadaver. The structures from anterior to posterior were renal artery, renal vein and pelvis of ureter. Raju RS et al 12 also observed altered arrangement of hilar structures bilaterally. In the present study, we found accessory renal veins in two cadavers, one on right side and one on left. According to Julian Kabala and Carl Roobottom ${ }^{5}$ accessory renal veins occur in 1 in 8 live births and were more common on right side. Left accessory renal veins are usually retroaortic in position.

According to Decker \& Plessis, ${ }^{13}$ the renal artery origin was an important landmark in abdominal aortic aneurysm surgeries. Over $95 \%$ of such aneurysms arose below the level of origin of the renal arteries. In resecting abdominal aortic aneurysm, vascular clamp was placed on the aorta distal to the renal arteries.

\section{CONCLUSION}

The kidneys are the vital organs. Presence of accessory renal arteries was the most common anomaly. These were the end arteries. The knowledge of accessory renal vessels, their arrangement at the hilum and associated kidney anomalies like horse shoe kidney were useful for the urologists, general surgeons and vascular surgeons to do surgical procedures on and around the kidneys and renal vessels.

\section{REFERENCES}

[1] Datta AK. The Urinary system. In: Essentials of human anatomy. Thorax and abdomen. Ch. 3, 7th edn. Kolkata: Current Books International 2006:272.
[2] Healy JC. Urogenital system. In: Standring S. edr. Gray's Anatomy. 40th edn. Ch. 74. Churchill Livingstone: Elsevier 2010: p. 1231.

[3] Patel U, Verma H. The kidney and adrenal gland. In: Butler P, Mitchell AWM, Healy JC. eds. Applied radiological anatomy. $2^{\text {nd }}$ edn. Ch. 12. Cambridge University Press 2013:223-4.

[4] Anderson JK, Cadeddu JA. Surgical anatomy of retroperitoneum, adrenals, kidneys and ureters. In: Wein AJ, Campbell. eds. Walsh Urology. 10th edn. Vol. 1, Ch. 1. Elsevier Saunders 2012: p. 26.

[5] Kabala J, Roobottom C. The kidneys and ureters. In: Sutton D. Textbook of radiology and imaging. $7^{\text {th }}$ edn. Vol. 2, Ch. 30. Churchill Livingstone: Elsevier 2011:9323.

[6] Moore KL, Persaud TVN. The developing human, clinically oriented embryology. 8th edn, New Delhi: Elsevier 2008:249-50.

[7] Romanees GJ. Cunningham's manual of practical anatomy. Thorax and abdomen. $15^{\text {th }}$ edn. Vol 2. New York: Oxford University Press 2013:167-78.

[8] Datta AK. The urogenital system. Essentials of human embryology. $5^{\text {th }}$ edn. Ch. 16. Kolkata: Current Books International 2007:220-21.

[9] Lee BJ, Rhee CM, Li-Li H. Ureteropelvic junction obstruction by an accessory renal artery: an under recognized but reversible cause of renovascular hypertension. Annals of Clinical and Experimental Hypertension. 2015;3(3):1028.

[10] Mehta G, Arole V. Accessory renal arteries: a cadaveric study. International Journal of Biomedical and Advance Research 2014;5(4):204-6.

[11] Kadir S. Angiography of the kidneys. Diagnostic angiography. Philadelphia: WB Saunders Company 1986:445-95.

[12] Raju RS, Kumar B, Ashish K, et al. Abnormal anatomical position and number of renal artery at the renal hilum. J Indian Acad Forensic Med 2015;37(2):187-9.

[13] Decker GAG, Du Plessis DJ. The kidneys, ureters and adrenals. Mc Gregor's L synopsis of surgical anatomy. 12th edn. ch. 23. Bombay: Varghese Publishing House 1999: p. 295. 